\title{
Developing a Conceptual Framework for Investigating Communication Supporting Community Resilience
}

\author{
Jenni Hyvärinen ${ }^{1}$ and Marita Vos ${ }^{2, *}$ \\ 1 Agora Center, University of Jyvaskyla, P.O. Box 35, Jyvaskyla FI-40014, Finland; \\ E-Mail: jenni.hyvarinen@jyu.fi \\ 2 Department of Communication, University of Jyvaskyla, P.O. Box 35, Jyvaskyla FI-40014, Finland \\ * Author to whom correspondence should be addressed; E-Mail: marita.vos@jyu.fi; \\ Tel.: +358-50-4410-358.
}

Academic Editor: Gregor Wolbring

Received: 10 April 2015 / Accepted: 8 July 2015 / Published: 15 July 2015

\begin{abstract}
In crisis management, cooperation within the response network is seen as crucial. Usually, this network refers to authorities and nongovernmental organizations, such as the Red Cross. However, the authors argue that to improve societal resilience one should take a broader overview of the actors involved in crisis preparedness and mitigation, and also include the public. With this in mind, the role of communication is scrutinized and a conceptual framework developed as a starting point for further investigation into how communication may be developed to strengthen a community approach to crisis management that includes citizen groups in the broader response network. A model is presented along with four propositions for future research. These include developing inventory methods to assist in stakeholder mapping in the pre-crisis phase, investigating all-hazard approaches to preparedness, scrutinizing collaboration during crisis situations to identify barriers to community resilience, and clarifying the kinds of communication competence needed in crisis situations and reflecting on lessons learned.
\end{abstract}

Keywords: community approach; community resilience; citizen response; response network 


\section{Introduction}

The purpose of this paper is to develop a conceptual framework for investigating communication that supports community resilience. Such a comprehensive framework is lacking, despite the attention currently paid to community engagement in crisis management [1]. Consequently, this study aims to clarify how communication can contribute to a community approach in crisis management and how this may be further investigated. In our view, including citizens in the crisis response network is vital. A community approach means that crisis management is seen as co-produced with citizens and that cooperation across the inter-organizational response network also includes citizen groups. Communication can be harnessed to support this collaboration. This notion is supported by the United Nations, which sees communication with communities in crisis situations as essential, as without it people "cannot access the help they need, make informed decisions or be effective leaders in their own recovery" [2] (p. 2).

A community approach is especially suitable in enhancing preparedness for natural disasters, as these are often characterized by their geographical location. All regions are susceptible to a particular type or types of natural disaster; for example, an area may be prone to floods, earthquakes, or storms. Educational activities that strengthen preparedness for disasters could focus on such natural disasters and seek to integrate preparedness for other types of crises.

Time pressure is a common feature of crises, and does not apply only to first response, as all crises phases involve more or less rapidly evolving events. Similarly, uncertainties and risks are a feature in all crisis phases. This requires flexible decision-making and openness to new developments that may occur. Such decision-making takes place within organizational boundaries and involves a wider network of stakeholders. Response organizations need to follow the evolving situation to see what can be done as well as monitor the effects of actions undertaken, including interaction with the public.

\section{Theoretical Background}

This paper is based on various approaches. The starting point is an integral approach to communication supporting crisis management. We also utilize the process approach of the Crisis and Emergency Risk Communication Model and link communication with changing needs throughout all the phases of a crisis. Furthermore, we approach communication as an interface function in the network of organizations and public groups. We explain these three approaches further in the following sections.

\subsection{Integral Approach to Communication Supporting Crisis Management}

Communication activities contribute to crisis management in various ways, including monitoring stakeholder needs, implementing communication activities with citizen groups and news media, and supporting communication in the response network. This integral type of approach has been used to develop a strategy map linking communication to crisis management by response organizations [3]. The objectives of communication in the strategy map include: (1) empowerment of various stakeholder groups, in particular citizen groups and organizations, to enable them to respond to crises, including through preventive actions and increased self-efficacy during a crisis; (2) increasing societal 
understanding of risks through educational activities and public debate on risks; (3) cooperation with citizens, organizations, and the various news media in response activities, for example in the case of evacuations and participative decision-making about reconstruction.

Disaster Risk Reduction has been a global strategy framework of the United Nations since 2000, and within this framework emphasis is placed on the importance of a community approach and social relations [4]. Communication is important to strengthen community social relations, with the overall goal of prevention and reduction of harm through exchange of messages in public relations programs and community campaigns [5]. This emphasizes the strategic function of communication for crisis management.

\subsection{Process Approach of Crisis and Emergency Risk Communication}

The Crisis and Emergency Risk Communication (CERC) Model [6] clarifies the tasks of communication throughout a crisis as the following: (1) pre-crisis risk messages, warnings, and preparations; (2) initial event uncertainty reduction and reassurance; (3) on-going support of personal response; (4) resolution updates and discussions about rebuilding efforts; and (5) evaluation and lessons learned. Although the linearity of phase models has been criticized [7] on the grounds that each crisis evolves differently, indicating communication tasks can nevertheless help in planning communication activities. The main value of the CERC model lies in integrating risk and crisis communication throughout all phases of a crisis [8].

Traditionally, risk communication focused on the period before the risk has materialized, while crisis communication has been seen as most relevant during the period after a crisis has occurred. Currently, however, risk and crisis are seen as a continuum. As risks often continue during the crisis phase, risk communication is considered relevant throughout all phases of an emergency [9], while crisis communication is seen as important in supporting crisis management in all phases of emergencies, also including the phase of pre-crisis preparedness [3]. This approach links together risk and crisis communication.

\subsection{Communication as an Interface Function in a Multi-Actor Network}

Communication can be seen as a strategic boundary-spanning function [10]. Such an interface function is needed because of the interdependencies that exist in social networks [11]. Networks are relational systems in which actors, e.g., persons or organizations, are embedded [12]. The focus can be on the structure of networks, but also on connections as a resource [13]. Such connections provide added value that can be seen as social capital in crisis situations. Response networks can be defined as multi-stakeholder networks. According to Roloff, "in multi-stakeholder networks actors from civil society, business, and governmental institutions come together in order to find a common approach to an issue that affects them all" [14] (p. 238). This also includes public-private collaboration, as suggested earlier in public-private social problem-solving alliances [15]. Coproducing safety calls for communication among the different actors, including governmental organizations, businesses, and civil society.

In times of crisis, communication across a response network that includes citizens facilitates sense-making about what has happened and reaching shared understandings on how to mitigate the 
situation. This resonates with stakeholder-enabling, in which community groups are included in a multi-stakeholder dialogue [16]. In an evolving crisis, people try to make sense of and come to terms with a rapidly changing reality [17]. Citizens combine information from various sources in trying to understand the current situation [18]. At play in such interaction are multiple realities and possibly also perceptual distortions [19]. Communication takes place in multi-actor arenas that include traditional as well as virtual media [20].

In each of the above three approaches, the emphasis is different. The first approach underlines the contribution of communication to crisis management, the second approach unites crisis and risk communication throughout all phases of the emergency, and the third approach starts from the notion of multi-stakeholder dialogue.

\section{Research Design}

This paper aims at developing a conceptual framework that can act as a starting point for further investigation into how communication can strengthen community resilience and include citizens in the response network. For this purpose, a number of core concepts was collated, following an earlier literature search conducted in peer-reviewed journals that focused on the keywords community resilience and citizen response, and how these were linked with the keyword communication [21]. As only 32 articles were found, many of which discussed communication in an implicit way, it was concluded that a deeper analysis was needed to identify directions for further research on this topic. Therefore, the literature found extended with sources found by snowballing provided the building blocks for this study, which aimed, first, to construct an initial model of how communication can support a community approach to crisis management, and second to identify potentially fruitful avenues for further research. This led to four propositions for future research.

\section{Core Concepts}

We explain the core concepts derived from the literature search below. These comprise empowerment, awareness and preparedness, resilience and citizen response, and individual and collective resilience.

\subsection{Empowerment}

The term empowerment is used, for example, in the field of psychology. Sadan [22] distinguishes individual empowerment, which is a process of the personal development of skills, abilities, and a positive self-definition, from community empowerment, which refers to the increased control of people as a collective over outcomes important to their lives. The latter is also understood as a process of capacity building towards greater control over the community's quality of life and wellbeing [23].

In the context of risks and crises, the term empowerment is also mentioned by various authors, such as Palenchar and Heath, who state that risk communication can "empower relevant publics by helping them develop and use emergency responses that can mitigate the severe outcomes in the event of a risk event" [24] (p. 127). 
Public organizations can develop empowerment policies to structurally facilitate citizen awareness of risks and preparedness by utilizing a community approach to connect with citizen groups and initiatives, and support citizen response by communication activities throughout all the phases of a crisis.

\subsection{Awareness and Preparedness}

Awareness of a risk is seen as a precondition for preparedness that can be enabled by communication and learning. Learning from one's own and others' experiences is an on-going process, as threats, vulnerabilities, and resources for response and recovery change over time [25]. Risks are intrinsically uncertain and risk perceptions differ across people; for example, people can be more or less fatalistic [4].

Four approaches have been proposed to increase awareness for the purpose of risk reduction [26]: (1) campaigns with a uniform, large-scale impact using standard messages; (2) engaging citizens in participatory learning; (3) informal education in communities and schools, involving the dissemination of standardized messages but with the flexibility to accommodate these to the needs of specific local audiences; and (4) formal school-based learning, where the curriculum content supports school disaster management and disaster risk reduction.

The concept of preparedness describes the process of developing resilience through, e.g., knowledge, resources, and relationships [27], which are "developed by governments, professional response and recovery organizations, communities and individuals to effectively anticipate, respond to, and recover from, the impacts" of disasters [28] (p. 21). Norris et al. [29] conclude that disaster readiness is, in fact, a matter of social change.

\subsection{Community Resilience and Citizen Response}

Community resilience is seen as linking a network of adaptive capacities for successful adaptation in the face of disturbance [29]. A resilient community is able to recognize unusual conditions, mobilize resources and self-organize in response to a crisis [30]. This needs to be done "in a timely and efficient manner, including through the preservation and restoration of its essential basic structures and functions" before, during, and after the crisis [28] (p. 24). Resources making for resilience include a well-developed economic system, social capital, and community competences; however, information and communication also facilitate adaptation [29,31].

Community resilience has individual and collective elements that are considered inter-related in the crisis management literature. Individual elements include personal features, such as social competence, problem solving, autonomy, self-efficacy, and sense of the future and purpose, that can be promoted by contextual, environmental influences such as family and the local community [32]. Collective elements stem from empowerment created in social networks that facilitate collective community behaviour and in this way increase community resilience to disasters [32].

Citizen response is a result of resilience as it "pertains to all actions taken by citizens, preparing for disasters and major accidents, during and after disasters and major accidents, with the intent to help themselves or others to limit the effects of the disaster or major accident" [33] (pp. 98-99). 


\section{Strengthening the Role of Communication in a Community Approach}

The sources found discussed different views on how communication could contribute to a community approach. McGee advocates strengthening the relationships between government agencies and local residents for the purpose of information sharing [34]. As it is difficult for authorities to create meaningful relations with numerous individuals, intermediaries may be utilized. In times of crisis, people may turn to such intermediaries. To this end, for example, teachers, nurses, and volunteers can be risk-educated [35]. Similarly, Veil et al. [8] suggest engaging civil society through intermediary organizations, such as youth groups, corporations, schools, neighborhoods, and churches, in preparedness programs. Inclusiveness principles underline the importance of including vulnerable groups in preparedness activities and throughout all stages of a crisis. In this way, crisis communication can strengthen community resilience on the level of family, neighborhood, and wider community networks [36]. A similar argument has been made for grassroots community engagement [37].

Boin and McConnell [38] propose building multiple partnerships that facilitate an "organic" community response, including public private collaboration. Collaboration of this kind crosses boundaries and connects different social networks. When "response networks" are mentioned, the focus is usually on inter-organizational collaboration. However, in community resilience, citizens are also seen as an integral part of the social networks that co-create safety. As explained above, communication is seen as an interface function that facilitates such partnerships. Information exchange within resilience networks may create trust and serve as a basis for cooperation. Building trust needs attention before crises occur and calls for open communication and dialogue among all actors [39].

A crisis is seen as a continuing process starting in the pre-crisis phase, culminating in the crisis or emergency phase, and ending in the post-crisis phase [40], whereas communication tasks differ across these phases [6]. In the pre-crisis phase, communication can enhance empowerment by strengthening community networks. Concretely, citizens can be engaged in preparedness activities, e.g., via societal or local campaigns [24] and trust created among different actors, including citizens, in the response network. In order to communicate effectively during crises, partnerships need to be created in advance [41]. Hence, during crises, communication can support co-operation not only within the network of organizations involved, but also with the public by co-creating situational awareness and providing timely information and instructions for action from trusted information sources. After crises, communication can support collaboration in the recovery phase and enhance learning for future situations, e.g., by giving shared meaning in the form of communal narratives to a recently experienced crisis [29].

On the basis of the thinking outlined above, the role of communication in supporting community resilience can be conceptualized as shown in Figure 1.

Empowerment calls for effective response networks that also involve civil society in all the phases of a crisis. Communication serves as an interface function within response networks, between public and private organizations and between organizations and citizen groups. In the pre-crisis phase, it focuses on awareness of risks and preparedness, aiming at enhanced community resilience and citizen response during and after the crisis. 


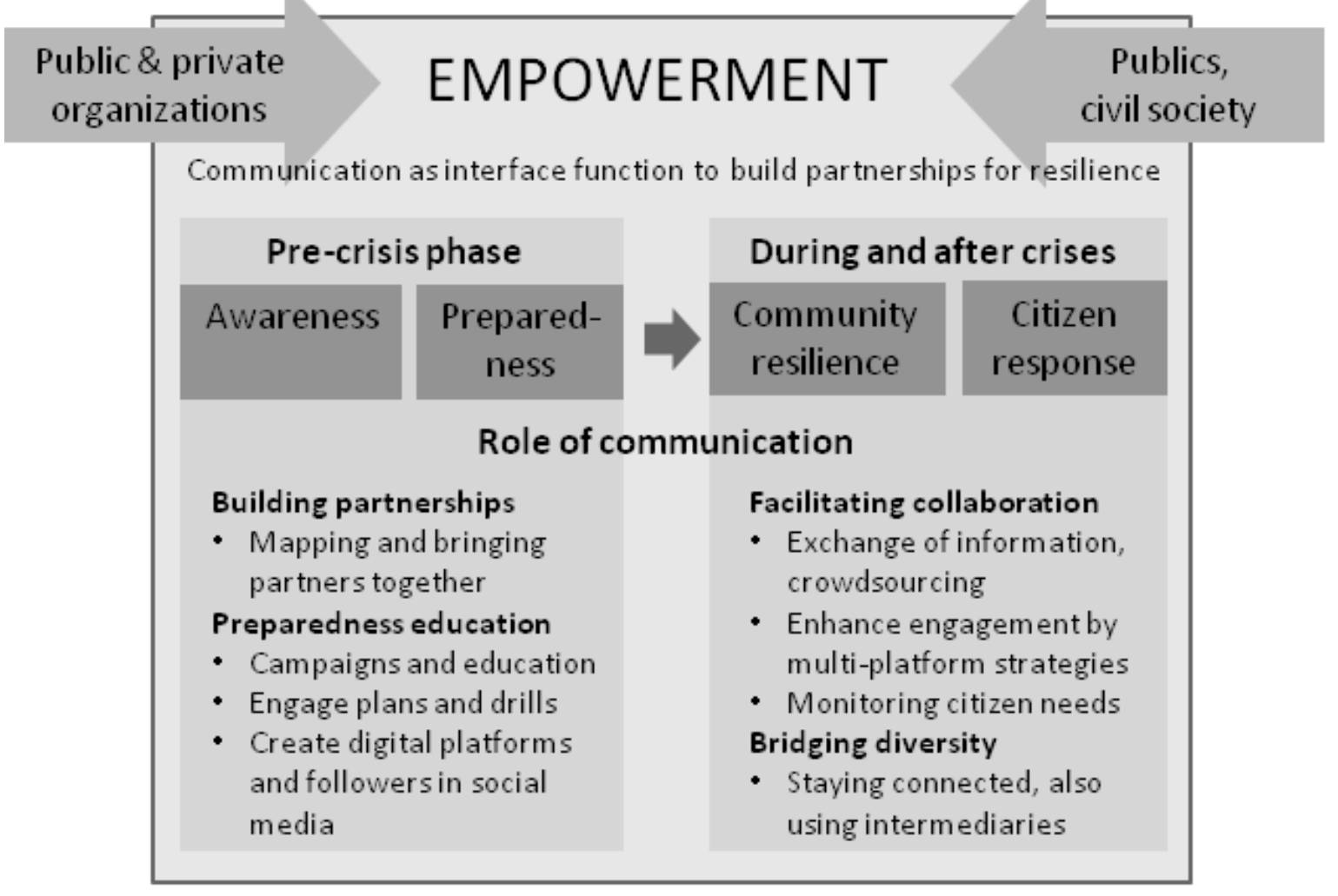

Figure 1. Communication facilitating community resilience.

In the pre-crisis phase, the emphasis is on building partnerships, by mapping potential for collaboration and bringing parties together. Preparedness activities include initiating campaigns and educational activities, and engaging citizens in crisis plans and drills. This also includes setting up dedicated websites and social media platforms with followers before a crisis occurs.

During and after crises, collaboration is enhanced by exchange of information, crowdsourcing (soliciting contributions by the public for crisis mapping), use of supportive multi-platform strategies to instruct and share experiences, and monitoring of citizen needs. Communication activities also aim at bridging the diversity within the broad response network, by ensuring connectedness of the partners and, where needed, involving trusted intermediaries.

\section{Investigating the Role of Communication in Enhancing Community Resilience}

To support the community approach to resilience, the interface function of communication in these social networks needs to be strengthened and investigated. In the following four subsections, we discuss ways in which this might be done, each subsection ending in a condensed proposition for further research.

\subsection{Building Partnerships in the Pre-Crisis Phase}

In the literature, community resilience is depicted as a network characteristic, as will be further explained. Resilience is created in a constellation of social networks that may have different layers, such as networks among authorities and networks of communities or civil groups on the local, regional and (inter)national level. This also demands meaningful partnerships between communities and 
government agencies [42]. What shapes these multi-actor networks need to be mapped in each situation. Thus, community resilience emerges from the adaptive capacities of different kinds of social networks, from grass-roots groups and neighborhoods to larger institutions and areas [29].

Many different kinds of groups and civil society organizations may be involved in crisis management or preparedness activities, such as more or less organized volunteers [43] with an interest in crisis management, or groups that do not focus on resilience but organize related educational activities. The United Nations Hyogo Framework for Action led to national platforms for disaster risk reduction that unite civil society organizations. However, this does not guarantee that different types of local citizen groups and trusted intermediaries will also be involved in the pre-crisis phase. By including all relevant organizations and citizen groups, a broader overview of the (in)tangible resources available for mitigating crisis situations can be obtained. Often, it is unclear who should be involved and in what manner. Research could focus on developing methods for stakeholder mapping that supports this requirement.

Proposition 1: As integrated intervention maps need to be made with the potential input of all the relevant actors, e.g., local volunteer groups and companies, thereby laying a broader foundation for crisis plans, inventory methods should be developed that assist in mapping the stakeholders to be involved in the process.

\subsection{Preparedness Education}

In preparedness education, the division of tasks between response organizations and citizens differs. Response organizations aim to provide the infrastructure for community resilience, and make a coordinated community-wide response possible [44]. Usually, they take care of specialist tasks needing special training. They also prepare for crises with a low probability but high impact, as it is difficult to motivate citizens for this purpose, while such tasks often need collaboration on a national or international level. Therefore, preparedness activities for citizens focus primarily on high probability crises within public memory. Such activities are often initiated by nongovernmental volunteer organizations, schools, and public health institutes. Authorities can facilitate and link their preparedness campaigns with such bottom-up initiatives.

Integrating preparedness into a broader "all-hazard" approach that includes various types of risks, while seen as promising in practice, is nevertheless in need of further scrutiny. Ethical aspects, for example, need attention in order to prevent stereotyping of minorities [45] and avoid widening the gap between conflicting world views, while communication on a terrorist threat needs a balance of warning messages and messages that promote tolerance [46]. It has also been proposed that a variety of methods of community engagement and collaboration be explored that take into account the diversity of communities and their prior experience of hazards [1].

Proposition 2: For preparedness, the effects of all-hazard approaches in communication, with a focus on local high probability crises, should be further investigated. Attention could also be paid to how, in such an approach, community diversity is addressed. 


\subsection{Facilitating Collaboration During and After Crises}

A community approach in crisis management calls for a broad response network comprising the various organizations and citizen groups involved. Collaboration for crisis response can be structured in a number of different ways. In development work over the last quarter-century, community-based approaches have been adopted and elaborated [47]. Activities in this domain often focus on poor communities in risk-prone areas in developing countries and are supported by nongovernmental organizations. Communication activities in western countries often emphasize mass-media approaches, although these currently seem to be effective only if well-linked to activities and perceptions of citizens. Community approaches have been little investigated in western countries. A Swedish study showed that while interest in community approaches for crisis management had increased, resources for local collaboration were lacking [43]. In the USA, the 'Whole Community Approach' was developed with the aim to bring residents, emergency management practitioners, business and community leaders, and government officials together to achieve a collective understanding of the needs of their respective communities and empower local action through communication [48]. The results of a study investigating community responses after Hurricane Katrina confirmed the importance of local knowledge and cooperative strategies, and the authors concluded that more research is needed to understand how communities' strengths and capabilities can be integrated into emergency management processes [42].

It should also be noted that, during crises, network boundaries and division of tasks are fluid. Authorities are increasingly aware of the fact that it takes the involvement of all parties to successfully reduce the threats posed by crises, and that reflection on cooperation enhances efficiency. In practice, when involving citizens in the process of crisis management, the boundaries between these and response organizations are not always clear. Unaddressed needs may be taken care of by 'shadow responders', who come from households, friends and family, neighborhoods, nongovernmental and voluntary organizations, businesses, and industries [49]. Responders often volunteer to do more than is expected, while volunteers can operate like experts and may fulfill similar tasks.

Research has shown that coordination of the various response organizations, agencies, and civil actors involved remains a challenge [50]. ICT systems to collate input from different sources have been developed, but further work is needed to clarify how they can facilitate cooperation between the actors involved [1]. The further development of communication activities would benefit from an exchange of insights and experiences in supporting community approaches gathered in different locations.

Proposition 3: Scholars should explore the collaboration of organizations with citizens during crises to identify barriers to community resilience in, for example, case studies.

\subsection{Bridging Diversity in the Broad Response Network}

A cooperative and flexible approach is needed to bridge cultural differences among different organizations in the response network. Organizations that in regular circumstances work relatively autonomously and have developed their own organizational culture to fit in with their regular operations may have various protocols and long established practices in place for arranging their 
collaboration with other bodies. In a crisis situation, however, they will have to build new collaborative arrangements, including the public, in order to deal with cultural differences experienced along the way.

On the one hand, community resilience requires preparedness through strategic planning to bring together resources for various risk scenarios. On the other hand, it should be noted that crisis situations are often complex and highly diverse, which poses challenges for crisis preparedness planning. A flexible leadership style on the part of the organizations involved is needed to adapt to evolving emergency situations. However, many authority response organizations have a culture of command and control, which makes it difficult to improvise when structures collapse in times of crisis [51]. The response style needs to fit the challenges that arise; this is achieved by making sense of the unfolding event [52]. Topper and Lagadec state that people are needed "who relish the challenge of creative thinking and action, even in the most inconceivable and rapidly developing contexts" [19] (p. 14). The unpredictable nature of crises requires improvisation, creative thinking, and unconventional solutions [18].

Communities need to build "effective and trusted information and communication resources that function in the face of unknowns" [29] (p. 143). Complex crises need an amalgam of different types of resources, which means inviting the involvement of various organizations and citizen groups. Next to collaboration within the authority response network, cooperation with the public also needs to be developed. It is argued that engaging citizens and affected communities requires a shift in the culture of public administration [53]. Some authorities hesitate to involve citizens in response activities, as they fear that citizens will not act rationally during crises. However, research shows that the notion of a panic-prone public is a myth [54]. Although some act intuitively and others more analytically, most lives are saved by "average" citizens, especially in initial aid [31].

The coproduction of crisis management depends on a crisis communication competence that facilitates interaction between organizations and citizens. This also includes familiarity with various platforms for sharing information and ensuring ethical and secure procedures [55]. Research can clarify what types of competence are most needed during crises. Crisis communication competence is also needed after a crisis. Crisis situations can be seen as a threatening experience, but also as an opportunity for learning [40]. However, after a crisis there is a tendency to return to normal life. It might be worth investigating what communication competences could facilitate joint reflection on lessons learned.

Proposition 4: Crisis communication competence is needed to enhance interaction between organizations and civil groups; this in turn needs to be further clarified to ensure the implementation of strategies for public engagement and collaboration.

\section{Conclusions}

The comprehensiveness of current crisis management networks calls for attention to be paid to communication, not only to facilitate inter-organizational cooperation but also collaboration with and engagement of citizens. Thus, empowerment can also be seen as a concept that can be deployed to improve the interface between the multi-actor networks comprising response organizations and civil society actors. In fact, because the boundaries between response organizations and civil society are 
somewhat blurred, there often is a myriad of locally different social networks with more or less interrelated layers.

Empowerment is created in social networks via building awareness and preparedness in the pre-crisis phase, which then enables citizen response and facilitates community resilience during and after a crisis. Communication may strengthen cooperation in the broad response network by enhancing joint preparedness, response, and recovery activities. Communication activities are employed to aid in collaboration and building trust in response networks and strengthening community resilience. In the pre-crisis phase, the emphasis is on building partnerships and enhancing preparedness education. Organizations involved in crisis management need to connect with citizen initiatives, take citizen risk perceptions into account, and involve citizens in decision making on priorities in risk management. During and after crises, collaboration can be facilitated and diversity in the broad response network bridged by communication. This calls for joint mapping of resources, arranging meetings and platforms to bring different kinds of social capital together, as well as engaging citizen groups in recovery activities and related decision making, for example, on how to rebuild a neighborhood.

To strengthen the community approach to resilience, the interface function of communication in these broad response networks should be further investigated. To this end, four propositions were formulated. These include such topics as developing inventory methods to assist in stakeholder mapping in the pre-crisis phase, investigating all-hazard approaches to preparedness, scrutinizing collaboration during crisis situations to identify barriers for community resilience, and clarifying the kinds of crisis communication competence needed in crisis situations and reflecting on lessons learned.

\section{Acknowledgments}

The research project Public Empowerment Policies for Crisis Management (PEP) leading to these results acknowledges funding received from the European Community's Seventh Framework Programme under grant agreement number 284927.

\section{Conflicts of Interest}

The authors declare no conflict of interest.

\section{References}

1. Burnside-Lawry, J.; Akama, Y.; Rogers, P. Communication research needs for building societal disaster resilience. Aust. J. Emerg. Manag. 2013, 28, 30-35.

2. United Nations Office for the Coordination of Humanitarian Affairs. OCHA on Message: Communications with Communities; United Nations Office for the Coordination of Humanitarian Affairs: New York, NY, USA, 2013. Available online: http://www.unocha.org/aboutus/publications/other/\%251/80 (accessed on 2 April 2015).

3. Palttala, L.; Vos, M. Quality indicators for crisis communication to support emergency management by public authorities. J. Conting. Crisis Manag. 2012, 20, 39-51. 
4. Eiser, R.J.; Bostrom, A.; Burton, I.; Johnston, D.M.; McClure, J.; Paton, D.; van der Plight, J.; White, M.P. Risk interpretation and action: A conceptual framework for responses to natural hazards. Int. J. Disaster Risk Reduct. 2012, 1, 5-16.

5. Aldoory, L. The Ecological Perspective and Other Ways to (Re)Consider Cultural Factors in Risk Communication. In Handbook of Risk and Crisis Communication; Heath, R.L., O'Hair, H.D., Eds.; Routledge Taylor \& Francis: New York, NY, USA, 2009; pp. 227-245.

6. Reynolds, B.; Seeger, M. Crisis and emergency risk communication as an integrative model. J. Health Commun. 2005, 10, 43-55.

7. Chess, C. Organizational theory and the stages of risk communication. Risk Anal. 2001, 21, $179-188$.

8. Veil, B.; Reynolds, B.; Sellnow, T.; Seeger, M. CERC as a theoretical framework for research and practice. Health Promot. Pract. 2008, 9, 26S-34S.

9. Coombs, W.T. Crisis Communication and Its Allied Fields. In The Handbook of Crisis Communication; Coombs, W.T., Holladay, S.J., Eds.; Wiley-Blackwell: Oxford, UK, 2012; pp. 54-64.

10. Cornelissen, J.; van Bekkum, T.; Van Ruler, B. Corporate communications: A practice-based theoretical conceptualization. Corp. Reput. Rev. 2006, 9, 114-133.

11. Vos, M.; Schoemaker, H. Integrated Communication: Concern, Internal and Marketing Communication; Boom Lemma: The Hague, The Netherlands, 2011.

12. Granovetter, M. Economic action and social structure: The problem of embeddedness. Am. J. Sociol. 1985, 91, 481-510.

13. Borgatti, S.P.; Foster, P.C. The network paradigm in organizational research: A review and typology. J. Manag. 2003, 29, 991-1013.

14. Roloff, J. Learning from multi-stakeholder networks: Issue-focused stakeholder management. J. Bus. Ethics 2008, 82, 233-250.

15. Austrom, D.; Ladd, L. Issues management alliances: New responses, new values, and new logics. In Research in Corporate Social Performance and Policy; Post, J.E., Ed.; JAI Press: Greenwich, CT, USA, 1998; Volume 15, pp. 233-255.

16. Calton, J.M.; Kurland, N.B. A Theory of Stakeholder Enabling: Giving Voice to an Emerging Postmodern Praxis of Organizational Discourse. In Postmodern Management and Organization Theory; Boje, D.M., Gephart, R.P., Jr., Thatchenkery, T.J., Eds.; SAGE: Thousand Oaks, CA, USA, 1996; pp. 154-177.

17. Weick, K. Making Sense of the Organization; Blackwell: Malden, MA, USA, 2001.

18. Falkheimer, J.; Heide, M. Crisis Communicators in Change: From Plans to Improvisations. In The Handbook of Crisis Communication; Coombs, W.T., Holladay, S.J., Eds.; Wiley-Blackwell: Malden, MA, USA, 2010; pp. 511-526.

19. Topper, B.; Lagadec, B. Fractal Crises-A new path for crisis theory and management. J. Contingen. Crisis Manag. 2013, 21, 4-16.

20. Vos, M.; Schoemaker, H.; Luoma-aho, V. Setting the agenda for research on issue arenas. Corp. Commun.: Int. J. 2014, 19, 200-215.

21. Hyvärinen, J.; Vos, M. Communication Concerning Disasters and Pandemics: Co-Producing Community Resilience and Crisis Response. In Handbook of International Crisis Communication 
Research; Schwarz, A., Seeger, M., Auer, C., Eds.; Wiley-Blackwell: Hoboken, NJ, USA, 2015, forthcoming.

22. Sadan, E. Empowerment and Community Planning: Theory and Practice; Hakibutz Hameuchad: Tel Aviv, Israel, 2004. Available online: http://www.mpow.org/ (accessed on 11 August 2014).

23. Kasmel, A.; Tanggaard, P. Conceptualizing organizational domains of community empowerment through empowerment evaluation in Estonian communities. Societies 2011, 1, 3-29.

24. Palenchar, M.J.; Heath, R.L. Strategic risk communication: Adding value to society. Public Relat. Rev. 2007, 33, 120-129.

25. Wilbanks, T.J.; Kates, R.W. Beyond adapting to climate change: Embedding adaptation in responses to multiple threats and stresses. Ann. Assoc. Am. Geogr. 2010, 100, 719-728.

26. International Federation of Red Cross and Red Crescent Societies. Public Awareness and Public Education for Disaster Risk Reduction: A Guide; International Federation of Red Cross and Red Crescent Societies: Geneva, Switzerland, 2011. Available online: http://www.ifrc.org/Global/ Publications/disasters/reducing_risks/302200-Public-awareness-DDR-guide-EN.pdf (accessed on 2 April 2015).

27. Paton, D.; Parkes, B.; Daly, M.; Smith, L. Fighting the flu: Developing sustained community resilience and preparedness. Health Promot. Pract. 2008, 9, 45S-53S.

28. United Nations International Strategy for Disaster Reduction. UNISDR Terminology on Disaster Risk Reduction; United Nations ISDR: Geneva, Switzerland, 2009. Available online: http://www.unisdr.org/we/inform/publications/7817 (accessed on 2 April 2015).

29. Norris, F.H.; Stevens, S.P.; Pfefferbaum, B.; Wyche, K.F.; Pfefferbaum, R.L. Community resilience as a metaphor, theory, set of capacities, and strategy for disaster readiness. Am. J. Commun. Psychol. 2008, 41, 127-150.

30. Heath R.L.; Palenchar, M.; O’Hair, H.D. Community building through risk communication infrastructures. In Handbook of Risk and Crisis Communication; Heath, R.L., O’Hair, H.H., Eds.; Routledge: New York, NY, USA, 2009; pp. 471-487.

31. Bajayo, R. Building community resilience to climate change through public health planning. Health Promot. J. Aust. 2012, 23, 30-36.

32. Boon, H.J.; Cottrell, A.; King, D.; Stevenson, R.B.; Millar, J. Bronfenbrenner's bioecological theory for modelling community resilience to natural disasters. Nat. Hazards 2012, 60, 381-408.

33. Helsloot, I.; Ruitenberg, A. Citizen response to disasters: A survey of literature and some practical implications. J. Conting. Crisis Manag. 2004, 12, 98-111.

34. McGee, T.K. Public engagement in neighbourhood level wildfire mitigation and preparedness: Case studies from Canada, the US and Australia. J. Environ. Manag. 2011, 92, 2524-2532.

35. Vihalemm, T.; Kiisel, M.; Harro-Loit, H. Citizens' response patterns to warning messages. J. Conting. Crisis Manag. 2012, 20, 13-25.

36. Kirchenbaum, A. Generic sources of disaster communities: A social network approach. Int. J. Sociol. Soc. Policy 2004, 24, 94-129.

37. Rowel, R.; Sheikhattari, P.; Barber, T.M.; Evens-Holland, M. Introduction of a guide to enhance risk communication among low-income and minority populations: A grassroots community engagement approach. Health Promot. Pract. 2012, 13, 124-132. 
38. Boin, A.; McConnell, A. Preparing for critical infrastructure breakdowns: The limits of crisis management and the need for resilience. J. Contingen. Crisis Manag. 2007, 15, 50-59.

39. Sellnow, T.L.; Ulmer, R.R., Seeger; M.W.; Littlefield, R.S. Effective Risk Communication: A Message-Centered Approach; Springer Science+Business Media: New York, NY, USA, 2009.

40. Ulmer, R.; Sellnow, T.; Seeger, M. Effective Crisis Communication: Moving from Crisis to Opportunity; SAGE: Thousand Oaks, CA, USA, 2011.

41. Kapucu, N. Interagency communication networks during emergencies: Boundary spanners in multiagency coordination. Am. Rev. Public Adm. 2006, 36, 207-225.

42. Patterson, O.; Weil, F.; Patel, K. The role of community in disaster response: Conceptual models. Popul. Res. Policy Rev. 2010, 29, 127-141.

43. Linnell, M. Citizen response in crisis: Individual and collective efforts to enhance community resilience. Hum. Technol. Interdiscip. J. Hum. ICT Environ. 2014, 10, 68-94.

44. Kendra, J.M.; Wachtendorf, T. Elements of resilience after the World Trade Center disaster: Reconstituting New York city's emergency operations centre. Disasters 2003, 27, 37-53.

45. Stevens, G.; Agho, K.; Taylor, M.; Barr, M.; Raphael, B.; Jorm, L. Terrorism in Australia: Factors associated with perceived threat and incident-critical behaviours. BMC Public Health 2009, 9, $1-9$.

46. Veil, B.; Mitchell, K. Terror management theory: Promoting tolerance in campus safety campaigns. Int. J. Strateg. Commun. 2010, 4, 207-224.

47. Maskrey, A. Revisiting community-based disaster risk management. Environ. Hazards 2011, 10, 42-52.

48. Federal Emergency Management Agency. A Whole Community Approach to Emergency Management: Principles, Themes, and Pathways for Action; Federal Emergency Management Agency: New York, NY, USA, 2011. Available online: http://www.fema.gov/library/ viewRecord.do?id=4941 (accessed on 2 April 2015).

49. Colten, C.E.; Kates, R.W.; Laska, S.B. Three years after Katrina: Lessons for community resilience. Environment 2008, 50, 36-47.

50. Sellnow, T.; Seeger, M.W. Theorizing Crisis Communication; Wiley-Blackwell: Oxford, UK, 2013.

51. Dynes, R.R. Community emergency planning: False assumptions and inappropriate analogies. Int. J. Mass Emerg. Disasters 1994, 12, 141-158.

52. Lundberg, J.; Törnqvist, E.; Nadjm-Tehrani, S. Resilience in sensemaking and control of emergency response. Int. J. Emerg. Manag. 2012, 8, 99-122.

53. United Nations International Strategy for Disaster Reduction. 2011 Global Assessment Report on Disaster Risk Reduction: Revealing Risk, Redefining Development; United Nations Terminology on Disaster Risk Reduction; United Nations International Strategy for Disaster Reduction: Geneva, Switzerland, 2011. Available online: http://www.unisdr.org/we/inform/publications/19846 (accessed on 2 January 2015).

54. Perry, R.W.; Lindell, M.K. Understanding citizen response to disasters with implications for terrorism. J. Conting. Crisis Manag. 2003, 11, 49-60. 
55. United Nations Office for the Coordination of Humanitarian Affairs. Humanitarianism in the Network Age: Including World Humanitarian Data and Trends 2012; United Nations Office for the Coordination of Humanitarian Affairs: New York, NY, USA, 2013. Available online: http://www.unocha.org/hina (accessed on 2 April 2015).

(C) 2015 by the authors; licensee MDPI, Basel, Switzerland. This article is an open access article distributed under the terms and conditions of the Creative Commons Attribution license (http://creativecommons.org/licenses/by/4.0/). 